\title{
Emotional Experience and Interactive Design in the Workplace
}

\author{
Kuo-Pin Chen and Wen-Huei Chou \\ Graduate School of Computational Design \\ National Yunlin University of Science \& Technology \\ 123 University Road, Section 3, Douliou, Yunlin 64002, Taiwan, R.O.C \\ \{slayer80645, cristance\}@gmail.com
}

\begin{abstract}
The negative emotions accumulated at work are easily overlooked, and unknowingly influence our lives and health. Happy emotions, positive interactions, and pleasant experiences can all effectively provide some opportunities to prevent fatigue and mitigate negative emotions and troubles. This study uses User-Centered Design (UCD) to investigate the needs of office workers dealing with work pressure, in the hopes that improved design can improve actual working conditions. ORID and empathy maps were used to elicit relevant experience and needs from the participants. Results showed that office workers tend to a certain degree to project emotional qualities on physical aspects of their work space, including furnishings and decorations. In the second stage, the Semantic Differential Scale was used to identify research limitations and scope, and identify a clear design direction. Finally, this study presents recommendations for the appropriate application of interactive design in office environments with the aim to provide points of reference for designers working in similar areas.
\end{abstract}

Keywords: Office work stress, interactive design, emotional design, empathic design, user-centered design.

\section{Introduction}

Among Asian countries, people in Taiwan are known for putting in long hours at work, with workers in technology companies frequently working 12 hour days. Thus, office workers not only face rapid changes in technology and work patterns, but also face great pressure to work long hours. With workers spending more time at the office than nearly anyplace else, [10] the negative emotional effects of work pressure can accumulate unnoticed, but this does not mean they are insignificant. [9] Work pressure may affect an individual's mental and physical health, and also impact the organization's operation efficiency. The UK's Public and Commercial Services Union (PCS) reported that $67 \%$ of survey respondents work overtime, while over $25 \%$ indicated that they experience pressure not only from the office culture and work management practices, but also from other individuals, all of which can negatively 
impact the emotions of the people around them. This study examines the behavioral needs of office workers responding to workplace stress with the aim to use appropriate design to enable workers to effectively express their emotions, reduce negative feelings, reduce fatigue and improve work effectiveness. Thus, this research seeks to understand workers in office environments and identify their needs for stress relief, and thus determine the principles of interactive emotional design to reduce workplace stress.

\section{Related Work}

According to the World Health Organization (WHO), good physical and psychological health, along with strong social relations, are considered to be strong indicators of overall health and well-being. Good physical and mental health and happiness are all conducive to excellent work, family and living conditions and can give people a sense of security. Therefore, before investigating ways to reduce workplace stress, we first evaluate the mental health and emotional needs of workers to identify key factors in stress relief. Increased emphasis should be paid to internal factors, especially the views and thoughts of the workers themselves. Additional focus must also be put on spirit and thought, using external and internal mechanisms to provide workers with meaningful help in alleviating excessive workplace stress.

Brown [2] referred to Fromm's contention that deep emotional factors contribute to a sense of powerlessness and anxiety that people experience in their interaction with technology and society. Lasch [8] coined the term "narcissistic survivalism" to describe modern culture, suggesting that the demands of daily life and work lead people to engage in behavior that emphasizes self-protection, specifically characterized by selective apathy, emotional disengagement and lack of interest in the past or future. This can result in a "contradiction of self" reaction. When we encounter social stress in our daily life, it triggers a defense mechanism which minimizes the need for emotional engagement. Buechler [3] referenced Fromm's theory as the ideological foundation for a healthy lifestyle, suggesting that modern people have lost enthusiasm for healthy living. In The Revolution of Hope, Fromm [5] suggested that humanity is the ability of a person to express his self-realization according to his personal needs. This means that our eyes see what we need to see and our ears hear what we want to hear because our needs are generated based on our subjective views, and our spirit produces the required emotion. Buechler also believes that self-fulfillment includes rich life and emotional experience.

Our lives are shaped by technological artifacts, and science and technology have begun to mediate how people experience reality and the past. Bostrom [1] suggested that technological innovation is the main driving force for long-term economic growth, and that technological change is driving global trends such as population size, education, material living standards, and communications. Social and personal life has also been directly affected by science and technology including such aspects as 
entertainment, interpersonal relationships, morality and material comforts. Most technology is used to increase productivity. Thus, people are required to master new tools, no matter how complex, to continually increase their competitiveness and chance of professional success. Currently, many successfully designed modes of operation are based on natural human behavior, thus understanding human emotions and experience is extremely important to the complexity of modern technology.

McDonagh and Lebbon [11] suggest that the ultimate aim of design should be to meet peoples' emotional needs, improving quality of life, and conferring meaningful value to everyday situations or problems. Emotion is an important source of information for people. Regardless of whether one is creating or solving problems, or developing an interactive system, [13] emotions ultimately have a significant impact and designers must understand the user's experiential and emotional needs. Roy et al. [12] proposed that the continuously increasing complexity of technology raises the importance of natural interactive behavior and emotions. Stimulating user emotions through physical contact in everyday human interaction is an effective way of giving people a better sense of connectedness. Thus, we hope to use design to better allow people to see themselves and others in the process of interaction, thus bringing people closer together.

Positive emotions have many benefits - they can help people overcome stress, making them an important aspect to human curiosity and learning. Dewey [4] proposed the aesthetic as a type of experience in which beauty can emotionally move the user. Kim et al. [7] proposed that the meaning of design aesthetic lies not only in emphasizing the designer's intent but also includes the user's experience and emotional value. Triggering an emotional response in the user through aesthetics is an important aspect of design because emotion has a strong effect on the average user. Kim [6] mentioned that, to date, studies of interactive design basically focus on issues of utility and effectiveness but, to motivate sustained behavior on the part of the user, the interactive experience raised by the user's emotions is a key factor. Interest is not only an emotional reaction, but is also a holistic experience incorporating the individual's outlook, the social environment and human relationships. Interest and amusement are excellent motivators, and design elements use surprise and interest to attract the user's attention and leave a deep impression. This is a point in design which should not be disregarded.

\section{Method}

Empathic design methods are usually people-oriented research approaches featuring direct contact and interaction with potential users to ensure that the design adopts the user's viewpoint. The standard framework for empathic design is built on user-centered design methods, and is able to support and establish creative and comprehensible designs for users to engage with in daily life. This study uses ORIED and empathy maps to investigate the needs of office workers. The discussion revolves around their actual everyday experience and seeks to help them infer a group-wide consensus 
and emotions. Good design is based on a deep understanding of human needs. The two methods mentioned above can help us observe and identify unexpected viewpoints. At the outset, this research requires multifaceted development and ideas to ensure that the research and participants themselves identify solutions to problems and design requirements.

The focus group method was developed by the Institute of Cultural Affairs (ICA) as a process for exploring beneath the surface of a conversation. The hierarchical process goes through four stages: Objective, Reflective, Interpretive and Decisional, known by its acronym ORID. This kind of dialogue method can guide the formation of a decision-making consensus, thus reducing the frequency of reprimands or embarrassment, while enhancing the mutual learning experience and highlighting the value of dealing with the underlying problem. Empathy maps are a comprehensive tool that helps observers identify different viewpoints, thus facilitating the quick prototype development while identifying potential user demands. In discussions and guidance based on empathy maps, a description of the participants and key words are collected as the basis for the design direction. Observing users is the first step of empathetic design. Observing and learning the users' actions through user body language, spontaneous active responses or other non-verbal cues can overcome the limitations of traditional questionnaires for recording the expression of emotions, thus allowing users to offer innovative ideas which can be further elucidated for improvement and use.

\section{Workshop}

The workshop included eight participants, four men and four women with an average age of 25. Participants were all full-time office workers who indicated they were under stress at work. The workshop process lasted about 2.5 hours, beginning with ORID interaction and a ten-minute office-themed film. Watching the film encouraged participants to recall events they normally encounter at work, thus putting them in an appropriate frame of mind and mood. The ORID guidance framework includes a total of ten questions based on the content of the film and taken from the point of view of the main character of the film (see Table 1). The participants were asked to raise and discuss their own viewpoint and opinions, and to describe potential solutions. The participants' responses were recorded on stickers and placed on the discussion board (Fig. 1).

The focus group session helped create a common consciousness and personal links among the workshop participants, which facilitated the empathy map discussion where problems were categorized as belong to (1) seeing, (2) listening, (3) thinking and feeling, (4) doing, (5) gain and (6) difficulty. The items for each problem were related to the normal work conditions of each participant (Table 2). We invited a representative participant to draw portraits on paper, and categorize them as belonging to six regions for the purposes of discussion. We then asked the participants to answer the discussion questions in the context of these six regions, with the answers written on stickers and placed in the corresponding areas on the empathy map. Based on the 
participants' answers, we attempted to find a key element for an emotional interactive design that could be implemented in an office environment. The entire discussion process was open and free, with participants actively exchanging ideas. To avoid preconceived answers or concepts, participants were asked to answer the questions in reference to their internal needs and everyday work experience. The responses to the final questions were all items which the participants found interesting or which they felt they may need help with (Fig. 2).

Table 1. ORID questions (organized from the current research)

\section{Question Type Question Content}

Objective

1. In the film, Peter was late to work because of traffic, and he suffered a mild electric shock. What happened to him after he got to the office?

2. Which of his colleagues and superiors did Peter encounter?

3. What was Nelly using that upset Peter?

Reflective 1 . What emotions did Peter experience when facing his TPS report?

2. How did Milton (the uncle listening to the radio) react to Peter's request?

3. What adjectives can you use to describe the atmosphere at Initech?

Interpretive $\quad 1$. Why do Peter Michael and Nelly feel unhappy at work?

2. Why do Peter, Michael and Nelly slip out of the office during working hours for coffee?

Decisional 1. If you were Peter, how would you resolve the morale problems at work?

2. If you were Peter, what kind of changes would you like to make?

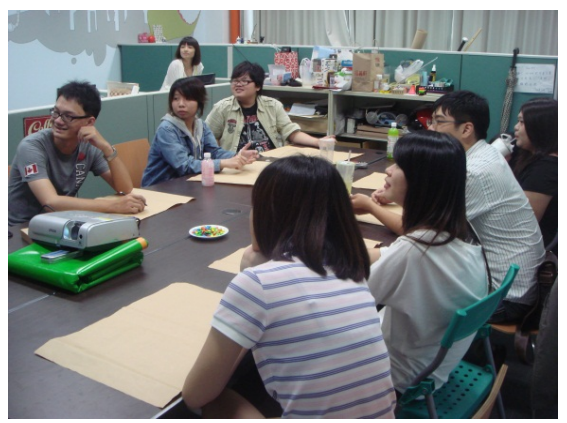

Fig. 1. Workplace documentary (arranged for this research) 
Table 2. Empathy map problems (arranged for this research)

$\begin{array}{ll}\text { Problem Type } & \text { Problem Content } \\ \text { See } & \text { 1. Reflect on your everyday office environment. What things do } \\ \text { you remember seeing that made you feel happy? } & \text { 2. What kinds of things do you keep at your desk for your own } \\ \text { enjoyment? } & \text { 1. At the office, what kinds of sounds make you unhappy or irri- } \\ \text { tated? } & \text { 2. What do your colleagues normally say to you? } \\ \text { Hear } & \text { 2. What do you feel is most important to you in the office? } \\ \text { Think and Feel } & \text { 1. What do you do most often at the office? } \\ \text { Say and Do } & \text { 2. What do you normally talk about at the office? } \\ \text { 1. At present, what kinds of things do you worry about most at the } \\ \text { office? }\end{array}$

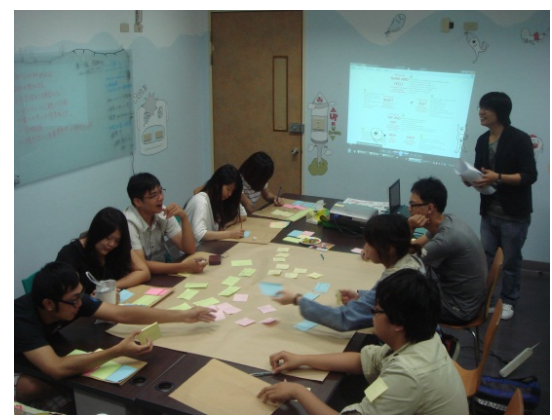

Fig. 2. Workplace documentary (arranged for this research)

\section{$5 \quad$ Analysis}

From the experimental results we obtained 326 concepts related to office work environments. The discussion process was unrestricted, thus many items had technical limitations such as improvements to office space configurations, changes to company systems, pay raises, adding vacation days, etc. None of these items fall within the scope of discussion in this study, and thus are seen as research limitations. The data was then categorized according the psychological demands proposed by Murray's requirements theory, while the empathy map was broken down into two large areas 
for positive emotions and negative emotions to facilitate identifying exactly which levels were positive demands for office workers, to serve as a reference for future design stages and thus enhance the positive demands of users. These two large categories were subdivided into target needs, material needs, power needs, emotional needs and information needs to locate the participant group's demand consciousness in one of these subcategories. To determine reasonable design scope and limitations, this study used the semantic differential method to identify more detailed and welldefined emotional elements, thus confirming the technical and physical conditions restraints, along with conditions not applied to office environments. SD analysis was used to obtain a high degree of user demand strength and apply currently available techniques to resolve design elements for office morale. The $\mathrm{X}$-axis is divided into technical rationality and irrationality, to increase the clarity of the design's technical goals. The Y-axis is divided into personal behavior and group behavior, which helps us identify the emotional needs of office workers. This falls under personal characteristics or, in the context of communication or interaction with others, group characteristics, thus providing indicators for design direction for personal use or group interactive use. Analysis results show that the, among the empathy map categories, items for "see", "hear", and "think and feel" are concentrated in the first quadrant (i.e., technical rationality and individual behavior), with creative desktop toys being the most frequently mentioned item (14 times) followed by music and interaction with others (Fig. 3).

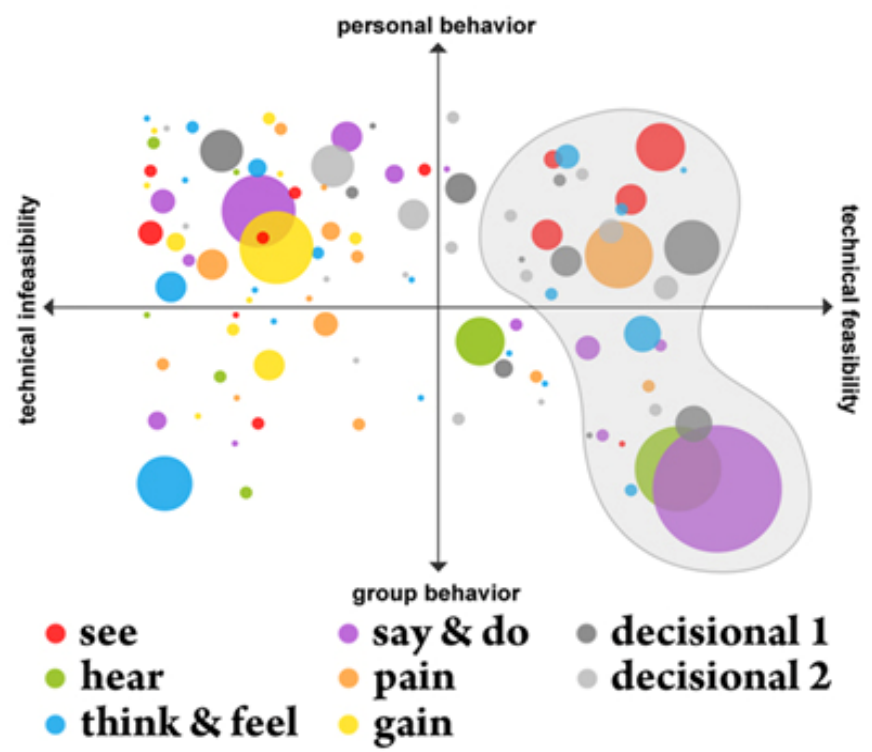

Fig. 3. Workplace documentary (arranged for this research) 
The results indicate that the majority appear in the quadrant of technical feasibility and group interaction, for which the more relevant corresponding demand theory classification is emotional needs and information needs. Thus, the analysis chart message prompted us to search for more convincing information. Some future design directions are summarized as follows: (1) The importance of emotional needs extends beyond an individual's emotional catharsis to also involve the emotional influence and interaction of the group. (2) The importance of information exchange is that it helps maintain morale by connecting workers through the exchange of messages. (3) Embedding emotions in design allows objects to change and grow alongside their users, providing a type of emotional sustenance. Thus, the above mentioned data analysis primarily obtains development directions for interactive designs which can be used to in actual office environments to meet the needs of office workers.

\section{Conclusion}

Modern science and technology has changed our socioeconomic system, compressing us into a type of controlled, consistent, unified unit. In this type of mechanical working environment, workers lose their personal uniqueness and creativity, and even the expression of personal feelings are subject to monitoring. This study starts from the viewpoint of emotional design, using empathic methods to identify the needs of office workers in an attempt to use design to re-trigger human emotions and further allow workers to express their feelings and relieve stress. In retrospect, the key point of this research is to identify design elements and strategies which can help office workers relieve work stress, to apply emotional design principles to fit these research results, and to find the intersection of interactive design and emotional design. This study raises a few important conclusions: for workers in office environments, emotional needs are an important consideration and must be taken seriously. The research results also provide the basic requirements for future creative design.

We hope that future research efforts can identify more convincing evidence tying user needs with design requirements and, more importantly, complying with the principles of emotional design to allow provide users with improved feedback and experiences in interacting with one another. This study focuses on the stress reduction needs of office workers. Data from a workshop developed using concepts from usercentered design was organized and analyzed to obtain the daily habits and behavior patterns for office workers which revealed some requirements and directions hidden among the data. Semantic differential analysis was used to propose a design concept prototype for key user goals among office workers, producing interactive design recommendations suitable for application in office environments. Thus, future work will discuss the following points: (1) Understanding the weekday habits and stressrelieving behavior of office workers. The habits of office workers when they come under stress at work, and the characteristics of how they interact with colleagues will inform effective recommendations for the design of relevant products. (2) Inducing the core design direction and requirements for office workers. Discussion workshops for office workers can be used to obtain design requirements and directions, thus 
improving the proposed interactive design prototype and making it more acceptable. (3) Formulating interactive designs concepts and suggestions suitable for use by office workers in an office environment. Future work needs to focus on office workers as the users of interactive design, and emphasize the details when proposing constructive references and implementing designs.

\section{References}

1. Bostrom, N.: The Future of Humanity Future of Humanity Institute. Oxford University Press (2007)

2. Brown, W.S.: Ontological Security, Existential Anxiety and Workplace Privacy. Journal of Business Ethics 23, 61-65 (2000)

3. Buechler, S.: Why We Need Fromm Today: Fromm's Work Ethic. Productive Orientation and Mental Health (2006)

4. Dewey, J.: Arts as Experience (1934)

5. Fromm, E.: The Revolution of Hope: Toward a Humanized Technology. Bantam Books, New York (1968)

6. Kim, J.W., Kim, Y.K., Nam, T.J.: The ténéré: design for supporting energy conservation behaviors. Paper Presented at the 27th International Conference Extended Abstracts on Human Factors in Computing Systems (2009)

7. Kim, T., Hong, H., Magerko, B.: Design requirements for ambient display that supports sustainable lifestyle. Paper Presented at the 8th ACM Conference on Designing Interactive Systems (2010)

8. Lasch, C.: The Minimal Self: Psychic Survival in Troubled Times. W.W. Norton, New York (1984)

9. Leka, S., Griffiths, A., Cox, T.: Work-related stress: the risk management paradigm: Organizational Health Psychology (2005)

10. Levey, R.E.: Sources of Stress for Residents and Recommendations for Programs to Assist Them. Academic Medicine 76 (2001)

11. McDonagh-Philp, D., Lebbon, C.: The emotional domain in product design. Design Journal 3(1) (2000)

12. Roy, M., Hemmert, F., Wettach, R.: Living interfaces: the intimate door lock. Paper Presented at the the 3rd International Conference on Tangible and Embedded Interaction (2009)

13. Sas, C., Zhang, C.: Do emotions matter in creative design. Paper Presented at the 8th ACM Conference on Designing Interactive Systems (2010) 